\title{
Killing of methicillin-resistant Staphylococcus aureus by low-power laser light
}

\author{
M. WILSON and C. YIANNI \\ Department of Microbiology, Eastman Dental Institute for Oral Health Sciences, University of London, \\ 256 Grays Inn Road, London WC1X 8LD
}

\begin{abstract}
Summary. The purpose of this study was to determine whether a methicillin-resistant strain of Staphylococcus aureus (MRSA) could be sensitised by toluidine blue O (TBO) to killing by light from a low-power helium/neon $(\mathrm{HeNe})$ laser. Suspensions containing $c .10^{10} \mathrm{cfu}$ of MRSA were irradiated with light from a $35 \mathrm{~mW}$ HeNe laser (energy dose: $0.5-2 \cdot 1 \mathrm{~J}$ ) in the presence of TBO $(1.6-12.5 \mu \mathrm{g} / \mathrm{ml})$ and the survivors were enumerated. The kills attained depended on both the light energy dose and concentration of TBO employed. A $4.47 \log _{10}$ reduction in the viable count was achieved with a TBO concentration of $12.5 \mu \mathrm{g} / \mathrm{ml}$ and a light dose of $2 \cdot 1 \mathrm{~J}$ (energy density $43 \mathrm{~J} / \mathrm{cm}^{2}$ ). MRSA were susceptible to killing by the laser light within $30 \mathrm{~s}$ of exposure to the TBO. The results of this study have demonstrated that MRSA can be rapidly sensitised by TBO to killing by HeNe laser light and that killing depends on the light energy dose and sensitiser concentration.
\end{abstract}

\section{Introduction}

Resistance of Staphylococcus aureus to methicillin became apparent in 1961 shortly after the introduction of the antibiotic and since then outbreaks of infection due to methicillin-resistant strains of the organism have been reported worldwide. ${ }^{1,2}$ Methicillin-resistant strains of $S$. aureus (MRSA) may also be resistant to several other antibiotics and vancomycin or teicoplanin is the drug of choice for systemic infections with such organisms. Management of patients with infections due to MRSA may involve not only the systemic administration of an appropriate antibiotic but also the application of topical antimicrobials to eliminate the organism from carriage sites, wounds or burns. $^{2}$ Unfortunately, antiseptics such as hexachlorophane, triclosan, chlorhexidine and povidoneiodine are not fully effective against MRSA and there is evidence of resistance developing to some of these agents. $^{3,4}$ One of the most promising agents for elimination of the organism from carriage sites is mupirocin, ${ }^{5}$ although development of resistance to this has also been reported. ${ }^{6}$ Therefore, new means of eliminating MRSA from colonised sites are required. We have shown that MRSA can be killed in vitro by low doses of light from a gallium aluminium arsenide ( $\mathrm{GaAs}$ ) laser when the organism has been treated with aluminium disulphonated phthalocyanine as a photo- sensitiser. ${ }^{7}$ The aim of this study was to determine the susceptibility of the organism to another laser/ photosensitiser combination-a helium/neon $(\mathrm{HeNe})$ laser in conjunction with toluidine blue $\mathrm{O}$ (TBO).

\section{Materials and methods}

\section{Bacterial strain}

The organism used in the study was $S$. aureus NCTC 11939 , a methicillin-resistant strain. This was maintained by weekly subculture on Nutrient Agar (Oxoid). For experimental purposes the organism was grown aerobically in nutrient broth at $37^{\circ} \mathrm{C}$ for $16 \mathrm{~h}$, harvested by centrifugation and resuspended in an equal volume of saline $0 \cdot 85 \%$.

\section{Laser and photosensitiser}

A $\mathrm{HeNe}$ gas laser (Spectra Physics, Hemel Hempstead) was used in the investigation. This had a power output of $35 \mathrm{~mW}$ and emitted light with a wavelength of $632.8 \mathrm{~nm}$ in a collimated beam with a diameter of $2.5 \mathrm{~mm}$. Toluidine blue O (C.I. 52040; Sigma) was used as a photosensitiser.

Effect of dye concentration on lethal photosensitisation

Aliquots $(100 \mu \mathrm{l})$ of a saline suspension of the 


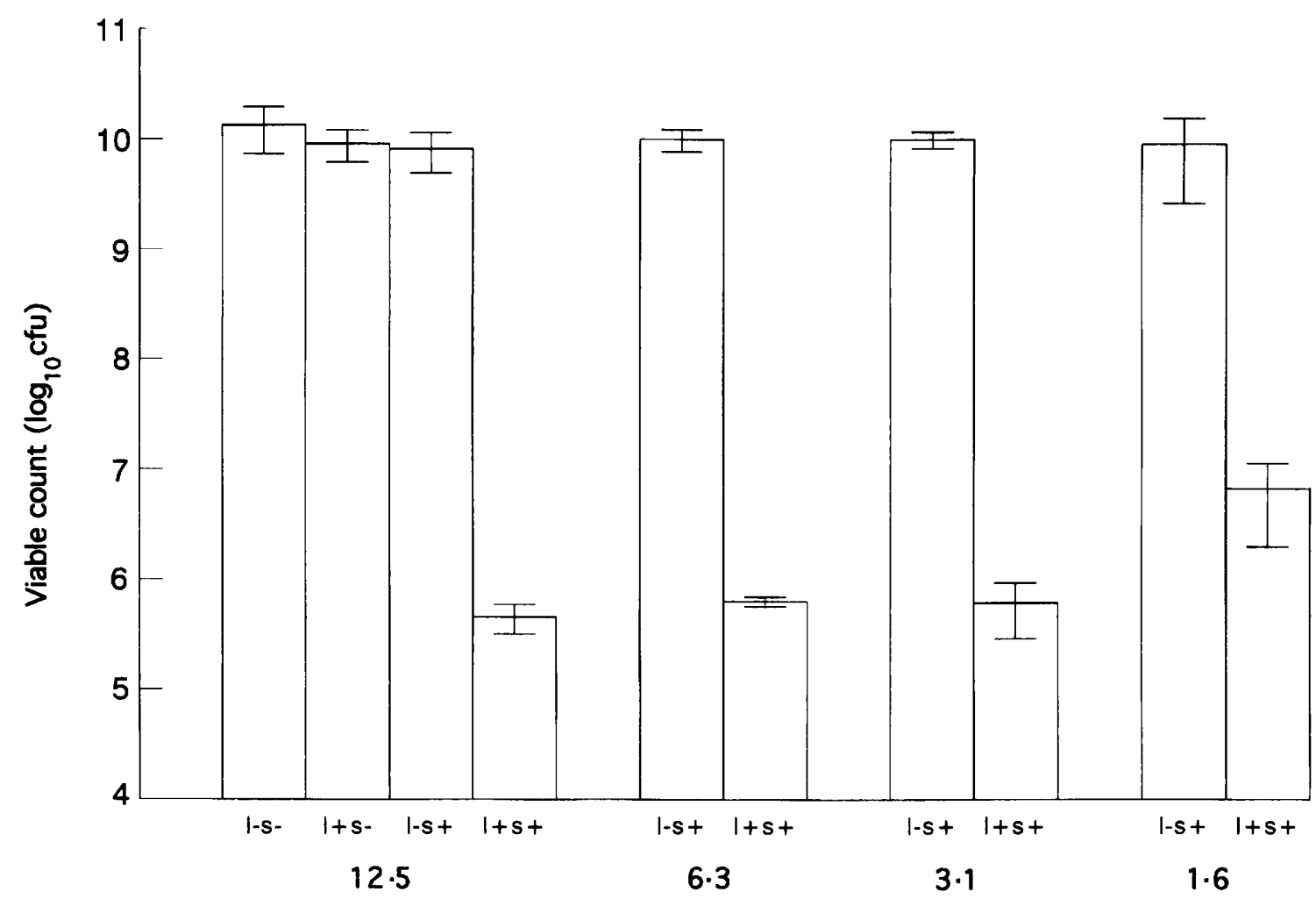

Toluidine blue $O$ concentration $(\mathrm{mg} / \mathrm{L}$ )

Fig. 1. Viable counts of suspensions of $S$. aureus before and after a 60-s exposure to light from a helium/neon laser (l) in the presence and absence of various concentrations of toluidine blue $\mathrm{O}(\mathrm{s}) .1-\mathrm{s}-$, suspensions exposed to neither sensitiser nor laser light; $1+\mathrm{s}-$, exposed to laser light in the absence of sensitiser; $1-s+$, exposed to sensitiser in the absence of laser light; $1+s+$, exposed to laser light in the presence of sensitiser. Bars represent mean values $(n=4)$ and $95 \%$ confidence intervals.

organism were transferred to wells of a 96-well, roundbottomed microtitration plate (Sterilin) and an equal volume of a filter-sterilised solution of TBO in saline $0.85 \% \mathrm{w} / \mathrm{v}$ was added to each well to give final concentrations of $1.6-12.5 \mu \mathrm{g} / \mathrm{ml}$. Magnetic stirrer bars $(4 \mathrm{~mm})$ were added to each well, the plate was placed on a magnetic stirrer and, after incubation for 5 min in the dark (pre-irradiation time; PIT), duplicate wells were exposed to laser light for $60 \mathrm{~s}(1+\mathrm{s}+)$. Control wells containing the bacterial suspension plus saline in place of the dye solution were treated in an identical manner to determine the effect of laser irradiation alone on bacterial viability $(1+s-)$. A further four wells, identical to those described above, were prepared and these were not exposed to laser light. Hence the effect on bacterial viability of the photosensitiser alone could be ascertained $(1-s+)$ and the initial concentration of bacteria in the suspension $(1-s-)$ could be determined.

After irradiation of appropriate wells, 10 -fold serial dilutions of the contents of each well were prepared in sterile Nutrient Broth (Oxoid) and duplicate 50- $\mu$ l samples were spread over the surfaces of Wilkins Chalgren (Oxoid) blood agar plates. After overnight incubation at $37^{\circ} \mathrm{C}$, the resulting colonies were counted.

\section{Effect of laser light exposure time on lethal photosensitisation}

The effect of laser light exposure time (from $15 \mathrm{~s}$ to $60 \mathrm{~s})$ on the kills attained was investigated by the above protocol. TBO was used at a concentration of $12.5 \mu \mathrm{g} / \mathrm{ml}$ and the PIT was $300 \mathrm{~s}$.

\section{Effect of pre-irradiation time on lethal photosensitisation}

With a dye concentration of $12.5 \mu \mathrm{g} / \mathrm{ml}$ and a light exposure time of $60 \mathrm{~s}$, the effect of varying the PIT (30-300 s) was determined.

\section{Statistical analysis}

Where appropriate, in each experiment the number of viable bacteria remaining after treatment with sensitiser $(1-s+)$, laser light $(1+s-)$ or a combination of both $(1+s+)$ was compared with that of the sensitiser-free, unirradiated controls $(1-s-)$ by Student's $t$ test.

\section{Results}

When $200 \mu$ l of a suspension of MRSA containing $1.3 \times 10^{10} \mathrm{cfu}$ was exposed to HeNe laser light for $60 \mathrm{~s}$ 


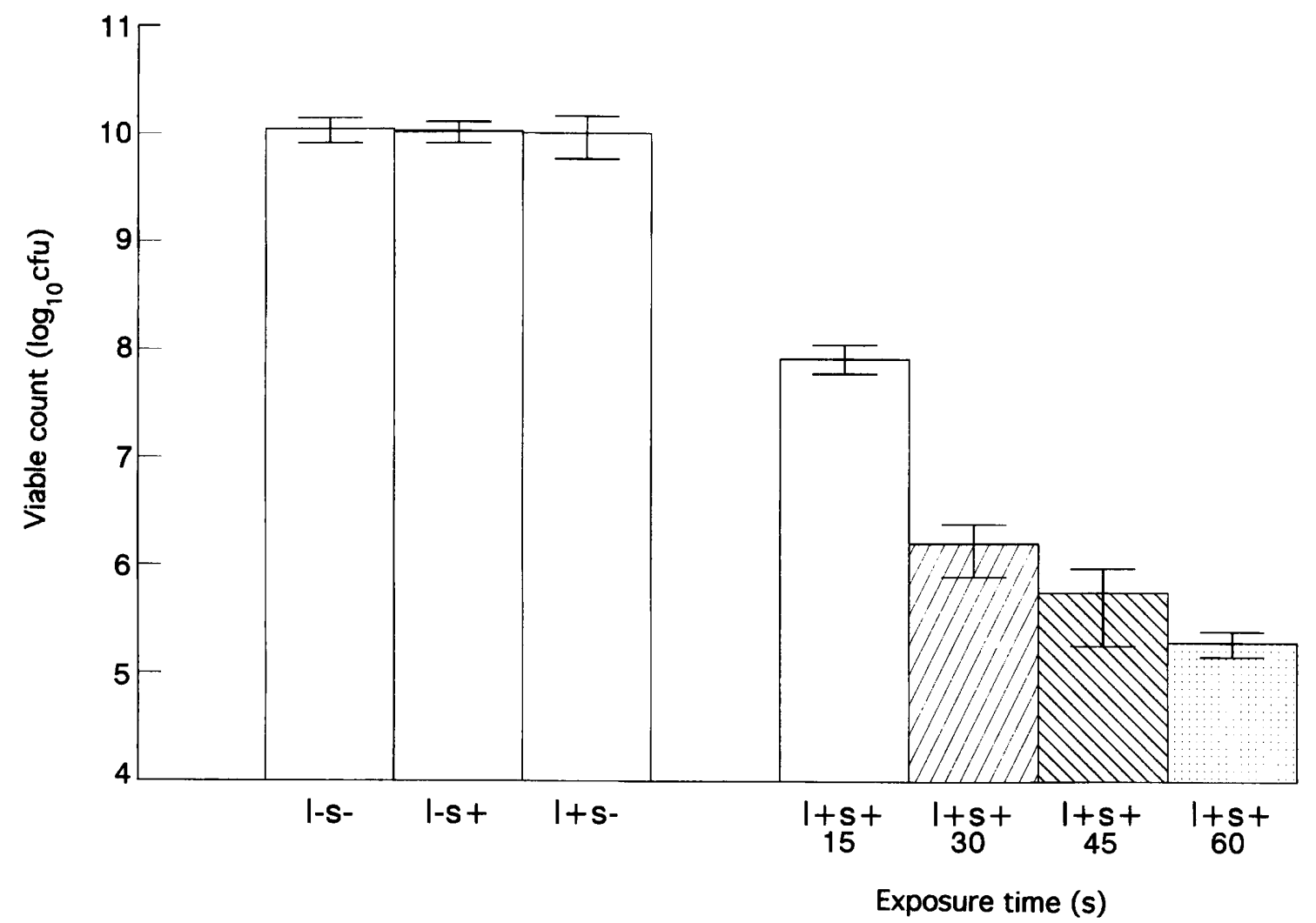

Fig. 2. Viable counts of suspensions of $S$. aureus before and after various periods of exposure to light from a helium/neon laser in the presence and absence of $12.5 \mu \mathrm{g} / \mathrm{ml}$ of toluidine blue $O$. Abbreviations as in fig. 1 .

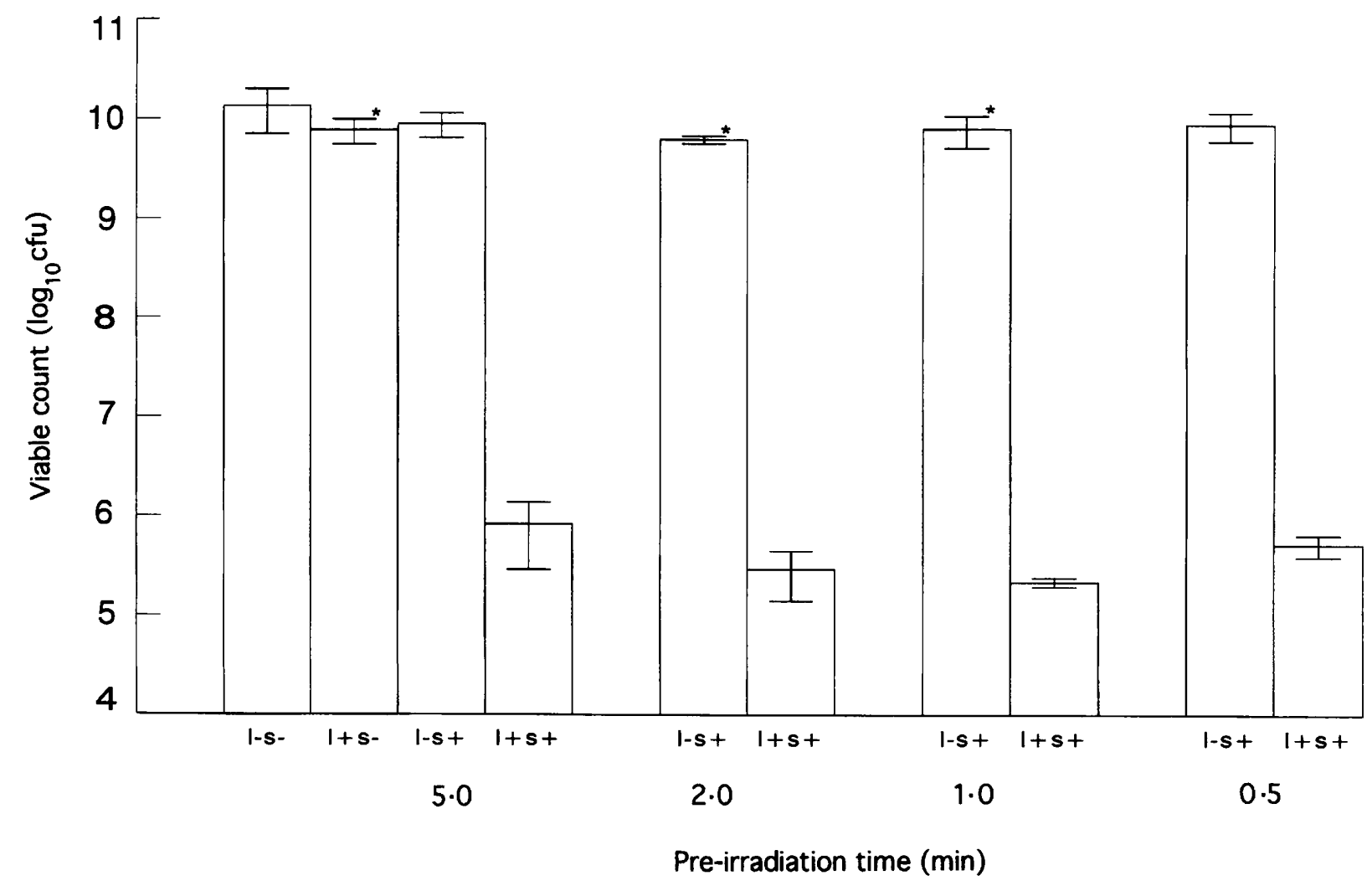

Fig. 3. Effect of pre-irradiation time on the viable counts of suspensions of $S$. aureus before and after a 60 -s exposure to light from a helium $/$ neon laser in the presence and absence of toluidine blue $012.5 \mu \mathrm{g} / \mathrm{ml}$. Abbreviations as in fig. 1 . Asterisk denotes that the viable count was significantly different from that of the control $(1-\mathrm{s}-$ ) suspension (Student's $t$ test, $0.01<\mathrm{p}<0.05$ ).

(energy dose $2 \cdot 1 \mathrm{~J}$; energy density $43 \mathrm{~J} / \mathrm{cm}^{2}$ ) in the presence of TBO at a concentration of $12.5 \mu \mathrm{g} / \mathrm{ml}$, a $\log _{10} 4.47$ reduction in the viable count was obtained (fig. 1). In the absence of laser light, the dye alone at this concentration achieved a $\log _{10} 0 \cdot 22$ reduction in viable count, and exposure of the bacteria to the laser 
light without dye being present resulted in a $\log _{10} 0 \cdot 17$ reduction. Neither of these reductions was statistically significant.

Decreasing the concentration of TBO to 6.3 or $3.1 \mu \mathrm{g} / \mathrm{ml}$ had little effect on the kills attained either in the dark $\left(a \log _{10} 0 \cdot 13\right.$ reduction in the viable count at both concentrations) or on exposure to $\mathrm{HeNe}$ laser light $\left(\log _{10}\right.$ reductions of 4.32 and 4.33 , respectively). At the lowest TBO concentration tested, $1.6 \mu \mathrm{g} / \mathrm{ml}$, the kill attained in the presence of laser light (a $\log _{10} 3.30$ reduction) was still considerable although slightly less than that attained at higher concentrations. TBO, in the absence of laser light, had no statistically significant effect on the viable counts at any of the concentrations used.

As can be seen from fig. 2, when the TBO concentration was held constant at $12.5 \mu \mathrm{g} / \mathrm{ml}$, the bacterial kills depended on the laser light exposure time. At the highest light energy dose employed $(2 \cdot 1 \mathrm{~J}$ at an energy density of $43 \mathrm{~J} / \mathrm{cm}^{2}$ ) a $\log _{10} 4.76$ reduction was obtained in the viable count of a suspension of MRSA containing $1 \cdot 1 \times 10^{10} \mathrm{cfu}$. The $\log _{10}$ reductions in viable counts obtained with exposure times of 45,30 and $15 \mathrm{~s}$ were $4 \cdot 29,3.84$ and $2 \cdot 13$, respectively. Corresponding $\log _{10}$ reductions in the viable count on exposure to either the laser light or TBO alone for $60 \mathrm{~s}$ were very small, amounting to 0.04 and 0.02 respectively. Neither of these reductions was statistically significant $(\mathrm{p}>0.05)$.

Variation in the period of incubation of the MRSA with TBO before irradiation with laser light had little effect on the kills obtained (fig. 3). Hence, the $\log _{10}$ reductions in the viable count with PITs of 30 and $300 \mathrm{~s}$ were $4 \cdot 41$ and $4 \cdot 21$, respectively. Exposure of the MRSA suspension to TBO in the absence of laser light had little effect on the viable count, the $\log _{10}$ reductions being $0.19(\mathrm{p}>0.05), 0.22(\mathrm{p}=0.04), 0.33(\mathrm{p}=0.01)$ and $0.18(\mathrm{p}>0.05)$ at PIT of $30,60,120$ and $300 \mathrm{~s}$, respectively. Exposure of the bacterial suspension to the laser light for $60 \mathrm{~s}$ in the absence of TBO caused a small $\left(\log _{10}\right.$ reduction $\left.0 \cdot 24\right)$, but statistically significant $(\mathrm{p}=0.03)$, reduction in the viable count when the PIT was $300 \mathrm{~s}$.

\section{Discussion}

The results of this study have shown that a methicillin-resistant strain of $S$. aureus can be killed by short-term exposure (15 s) to light from a low-power $\mathrm{HeNe}$ laser in the presence of low concentrations $(12.5 \mu \mathrm{g} / \mathrm{ml})$ of toluidine blue $O$. There have been several reports of the ability of TBO to act as a photosensitiser of bacteria. Mathews and Sistrom ${ }^{8}$ demonstrated that a toluidine blue-sensitised colourless mutant of Sarcina lutea could be killed by polychromatic light from tungsten and fluorescent lamps. Macmillan et al. ${ }^{9}$ found that both gram-positive (Sarcina lutea) and gram-negative (Escherichia coli and Pseudomonas aeruginosa) species could be killed by $\mathrm{HeNe}$ laser light in the presence of the dye. More recently, Wilson et al. ${ }^{10,11}$ reported that various TBOsensitised oral bacteria (Porphyromonas gingivalis, Fusobacterium nucleatum, Actinobacillus actinomycetemcomitans) could be killed by low doses of $\mathrm{HeNe}$ laser light. However, studies of the lethal photosensitisation of $S$. aureus have usually employed a polychromatic light source and haematoporphyrins as photosensitisers. In these circumstances killing invariably requires a high photosensitiser concentration and long irradiation times. For example, Bertoloni et al. ${ }^{12}$ reported a $\log _{10} 5$ reduction in the viable count of a suspension of $S$. aureus $\left(10^{9} \mathrm{cfu} / \mathrm{ml}\right)$ irradiated for $10 \mathrm{~min}$ with light from four $250 \mathrm{~W}$ tungsten bulbs in the presence of a haematoporphyrin derivative $(200 \mu \mathrm{g} / \mathrm{ml})$. The use of low-power lasers enables shorter light exposure times to be effective; appreciable kills of $S$. aureus can be attained with an exposure time of $60 \mathrm{~s}$ with an $11 \mathrm{~mW}$ gallium aluminium arsenide laser and aluminium disulphonated phthalocyanine as a photosensitiser. ${ }^{7}$ The results of the present investigation have shown that, with a suitable low-power laser, exposure times as short as $15 \mathrm{~s}$ can exert a considerable bactericidal effect in the presence of an appropriate photosensitiser. This is obviously an important factor in assessing the clinical applicability of this potential therapeutic approach. Another consideration in this respect would be the period of time required for the sensitiser to render the bacteria susceptible to killing by the laser light. This study has shown that sensitisation of MRSA occurs within $30 \mathrm{~s}$ of exposure of the organism to the dye. Toluidine blue $\mathrm{O}$ belongs to the phenothiazinium family of dyes (which includes methylene blue) and, as they are able to sensitise cancer cells to killing by light, considerable interest has been shown in the potential use of such dyes for the photodynamic therapy of tumours. ${ }^{13}$ Although several studies have reported the killing of tumour cells in vitro, few in-vivo studies have been performed. Williams et al. ${ }^{14}$ employed methylene blue as a sensitiser in the photodynamic therapy (PDT) of bladder cancer in man although the outcome was unsuccessful. In contrast, methylene blue proved to be an effective sensitiser in the PDT of tumours in mice. ${ }^{15}$ Its ability to sensitise Propionibacterium acnes to killing by laser light has also prompted a suggestion that it be used for the PDT of acne vulgaris. ${ }^{16}$ The ability of these dyes to sensitise mammalian cells to killing by light has obvious implications with respect to their use in the lethal photosensitisation of bacteria in vivo if extensive killing of adjacent host cells were to occur. However, no data are available regarding the relative susceptibilities of TBO-sensitised bacteria and mammalian cells to $\mathrm{HeNe}$ laser light. If the light energy doses and sensitiser concentrations required to kill bacteria are found to be lower than those needed to kill mammalian cells then this therapeutic window could be used to kill bacteria selectively without damaging adjacent host cells in vivo. An alternative strategy would be to target the bacteria by linking the 
TBO to antibodies against the MRSA. This approach, using the sensitiser $\mathrm{Sn}$ (IV) chlorin $\mathrm{e}_{6}$ linked to monoclonal antibodies against Pseudomonas aeruginosa, has been shown to be effective at selectively killing $P$ s. aeruginosa in the presence of $S$. aureus. ${ }^{17}$ Recently it has been reported that photoactive methylene blue-antibody conjugates can also be prepared. ${ }^{18}$ This strategy may also be advisable to reduce any possibility of damage to the DNA of host cells, although the cytotoxicity of light-activated toluidine blue (unlike methylene blue) appears to result from its

\section{References}

1. Cookson BD. MRSA: Major problem or minor threat? J Med Microbiol 1993; 38: 309-310.

2. Duckworth GJ. Diagnosis and management of methicillin resistant Staphylococcus aureus infection. BMJ 1993; 307: 1049-1052.

3. Cookson BD, Farrelly H, Stapleton P, Garvey RPJ, Price MR. Transferable resistance to triclosan in MRSA. Lancet 1991; 337: $1548-1549$.

4. Grosserode MH, Wenzel RP. The continuing importance of staphylococci as major hospital pathogens. J Hosp Infect 1991; 19Supp B: 3-17.

5. Hill RLR, Duckworth GJ, Casewell MW. Elimination of nasal carriage of methicillin-resistant Staphylolococcus aureus with mupirocin during a hospital outbreak. J Antimicrob Chemother 1988; 22 : 377-384.

6. Janssen DA, Zarins LT, Schaberg DR, Bradley SF, Terpenning MS, Kauffman CA. Detection and characterization of mupirocin resistance in Staphylococcus aureus. Antimicrob Ag Chemother 1993; 37: 2003-2006.

7. Wilson M, Pratten J. Sensitisation of Staphylococcus aureus to killing by low-power laser light. $J$ Antimicrob Chemother 1994; 33: 619-624.

8. Mathews MM, Sistrom WR. The function of the carotenoid pigments of Sarcina lutea. Arch Mikrobiol 1960; 35: 139-146.

9. MacMillan JD, Maxwell WA, Chichester CO. Lethal photosensitization of microorganisms with light from a continuous-wave gas laser. Photochem Photobiol 1966; 5: $555-565$.

10. Wilson M, Dobson J, Sarkar S. Sensitization of periodontopathogenic bacteria to killing by light from a low-power laser. Oral Microbiol Immunol 1993; 8: 182-187.

11. Wilson M. Photolysis of oral bacteria and its potential use in the treatment of caries and periodontal disease. $J$ Appl Bacteriol 1993; 75: 299-306. effects on the cytoplasmic membrane rather than on DNA, at least in bacteria and eukaryotic microorganisms. ${ }^{13,19,20}$

Although the results of this study have shown that MRSA can readily be killed by low doses of $\mathrm{HeNe}$ laser light, further evaluation of the approach is necessary, especially under conditions more closely related to the situation in vivo. Furthermore, the possibility of damage to host cells, at the light doses and sensitiser concentrations effective against bacteria, needs to be evaluated.

12. Bertoloni G, Dall'Acqua $\mathbf{M}$, Vazzoler $\mathbf{M}$, Salvato B, Jori G. Bacterial and yeast cells as models for studying haematoporphyrin photosensitisation. In : Andreoni A, Cubeddu R (eds) Porphyrins in tumour phototherapy. New York, Plenum. 1983: 177-183.

13. Tuite EM, Kelly JM. Photochemical interactions of methylene blue and analogues with DNA and other biological substrates. J Photochem Photobiol B: Biol 1993; 21 : 103-124.

14. Williams JL, Stamp J, Devonshire R, Fowler GJS. Methylene blue and the photodynamic therapy of superficial bladder cancer. J Photochem Photobiol B: Biol 1989; 4: 229-232.

15. Konig K, Bockhorn V, Dietel W, Schubert M. Photochemotherapy of animal tumors with the photosensitizer methylene blue using a krypton laser. J Cancer Res Clin Oncol 1987; 113: 301-303.

16. Konig K, Meyer H. Photodynamically induced inactivation of Propionibacterium acnes using the photosensitizer methylene blue and red light. Dermatol Monatsschr 1992; 178: $297-300$.

17. Friedberg JS, Tompkins RG, Rakestraw SL, Warren SW, Fischman AJ, Yarmush ML. Antibody-targeted photolysis. Bacteriocidal effects of Sn (IV) chlorin $\mathrm{e}_{6}$-dextranmonoclonal antibody conjugates. Ann NY Acad Sci 1991; 618: $383-393$

18. Moisenbocker M, Masuya $H$, Shimazu $H$, Miyawaki $T$, Ichimori Y, Sugawara T. Photoactive methylene blue dye derivatives suitable for coupling to proteins. Photochem Photobiol 1993; 58: 648-652.

19. Tuveson RW, Larson RA, Kagan J. Role of cloned carotenoid genes expressed in Escherichia coli in protecting against inactivation by near-UV light and specific phototoxic molecules. J Bacteriol 1988; 170 : 4675-4680.

20. Paardekooper M, Van den Broek PJA, De Bruijne AW, Elferink JGR, Dubbelman TMAR, Van Steveninck J. Photodynamic treatment of yeast cells with the dye toluidine blue: all-or-none loss of plasma membrane barrier properties. Biochim Biophys Acta 1992; 1108: 86-90. 